DOI: $\underline{10.17805 / g g z .2020 .3 .6}$

\title{
Сравнительный анализ систем образования в Российской Федерации и Китайской Народной Республике
} Е. Д. Гаврюшина

Московский гуманитарный университет

В статье проводится сравнительный анализ российской и китайской системы образования, выявлены ключевые образовательные проекты и методики, обозначены приоритетные направления развития.

Ключевые слова: образование; начиональный проект РФ «Образование»; Российская Федераџия; Китайская Народная Республика

\section{Comparative Analysis of the Systems of Education in the Russian Federation and the People's Republic of China}

E. D. Gavriushina

Moscow University for the Humanities

The article presents a comparative analysis of the Russian and Chinese systems of education. The author highlights the key educational projects and methodologies and specifies the priority development fields.

Keywords: education; national project of the Russian Federation "Education"; Russian Federation; People's Republic of China

\section{ВВЕДЕНИЕ}

Образование является неотъемлемой частью социокультурной, политической и экономической сфер. Оно служит отражением общественных процессов, движений и решений, которые происходят и принимаются внутри государства. Одним из главных факторов современных политических и экономических процессов стала глобализация. Представляя собой экономический процесс, она является важным катализатором трансформации всей системы образования с последующей интеграций зарубежного опыта и разработок, изменения этапов аттестации учащихся и переквалификации педагогов. Большой интерес к обмену интеллектуальным капиталом развитых и развивающихся стран сопровождается интернационализацией образования, что влечет за собой необходимость анализа, сравнения и выявления лучших образовательных технологий. 


\section{ОБРАЗОВАТЕЛЬНАЯ СИСТЕМА КНР}

Китайская Народная Республика находится в центре экономического и политического внимания на протяжении последних десятилетий. Мощный скачок в развитии легкой и тяжелой промышленности, превышение экспорта над импортом, рост ВВП, высокий спрос на китайских специалистов за рубежом - положительная динамика развития во многом обязана китайской системе образования (см., например: Экспорт Китая ..., 2020: Электронный ресурс; ..., Китай отчитался ..., 2020: Электронный ресурс).

С давних времен Китай славился известными философами и мыслителями, талантливыми изобретателями и учеными. В Поднебесной были изобретены предметы, впоследствии изменившие ход истории: бумага, компас, поpox, шелк и т. д. Открытия и наука во все времена творили историю, в XXI в. Китай стремительно наращивает обороты производства и вкладывает огромные средства для развития системы образования, которая входит в топ-10.

В 2015 г. были внесены последние правки в Закон Китайской Народной Республики об образовании, важным элементом которого является доступ к обязательному бесплатному девятилетнему образованию. Всеобщая грамотность населения - главная цель, которая была поставлена в 1950-е гг., на сегодняшний день приоритетной задачей для государства стал массовый выпуск не просто образованных, а квалифицированных специалистов, особое внимание уделяется управленческим кадрам (см.: Законы об образовании ..., б/д: Электронный ресурс).

Система образования в Китае состоит из четырех этапов:

1. дошкольное (детские сады);

2. обязательное школьное образование (предполагает 12 лет обучения и состоит из трех основных ступеней - начальная школа, средняя неполная школа, полная средняя школа (необязательная, в соответствии с финансовыми возможностями и наличием желания продолжать обучение);

3. высшее образование.

Обучение начинается с трех лет, именно в этот период закладываются традиционные культурные ценности. Детские сады делятся на государственные и частные. Отличительной чертой является стоимость обучения (частные дороже), количество детей в классах (в государственных группа состоит из 6070 человек). В госучреждениях акцент делается на воспитании трудовых навыков, преобладают коллективные игры, в частных - стараются найти индивидуальный подход и развить творческие способности. Патриотизм прививается с детства, поэтому каждое утро понедельника начинается с поднятия государственного флага под гимн КНР. В этот период жизни дети учатся писать, считать и читать, на выходе ребенок должен знать не менее 400 иероглифов. Китайская образовательная система строится, в первую очередь, на дисциплине. 
С раннего детства ребенок обязан строго придерживаться расписания и выполнять указания взрослых. Даже детские игры контролируются воспитателями. С точки зрения китайских учителей, такая строгость необходима для того, чтобы дети стали полноценными членами общества, смогли найти свое место в жизни и приносить своему народу максимальную пользу (Антиповский, Боревская, Франчук, 1980: 73).

С 6-летнего возраста начинается начальная школа и длится полных шесть лет, здесь учащиеся более подробно осваивают математику, родной язык, этику и естествознание, особое внимание уделяют физической подготовке. Следующий этап - средняя школа: с 12 лет дополнительно изучают общие предметы: физику, химию, географию и т. д. На этом бесплатный период обучения заканчивается, далее следует трехлетняя профильная подготовка к поступлению в вуз. Каждый переходный период сопровождается обязательной сдачей экзаменов. Учебные заведения общего образования аналогично делятся на государственные и частные. Так же, как и у младшего звена, отличается стоимость обучения, количество человек на одного преподавателя и направления подготовки.

Высшее образование с каждым годом становится доступнее, увеличивается количество направлений подготовки в учебных заведениях, также растет число абитуриентов. Китайское правительство уделяет огромное внимание развитию культуры, науки, техники, формированию узкопрофессиональных конкурентоспособных специалистов.

\section{ОБРАЗОВАТЕЛЬНАЯ СИСТЕМА РФ}

В 2018 г. Президент Российской Федерации В. В. Путин в послании Федеральному собранию обратил внимание на острую необходимость модернизации высшего и средне-специального образования с использованием современных технологий: «Опираясь на лучшие практики и опыт, нам нужно в короткие сроки провести модернизацию системы профессионального образования, добиться качественных изменений в подготовке студентов, прежде всего по передовым направлениям технологического развития, сформировать ступень “прикладного бакалавриата" по тем рабочим профессиям, которые фактически требуют инженерного образования, а также организовать центры опережающей профессиональной переподготовки и повышения квалификации для уже работающих граждан» (цит. по: Владимир Путин ..., 2018: Электронный ресурс).

Впоследствии экспертным сообществом был разработан национальный проект «Образование», включающий четыре основных направления модернизации системы: обновление содержания образовательных программ, создание современной высокотехнологичной инфраструктуры, подготовка и последую- 
щее трудоустройство высококвалифицированных специалистов, их переподготовка и повышение квалификации, а также разработка гибкой системы для эффективного управления данной сферой. Руководителем проекта была назначена заместитель председателя Правительства РФ Т. А. Голикова, срок реализации - до 31 декабря 2024 г. (см.: Национальный проект «Образование» ... , 2019: Электронный ресурс).

Главная цель проекта - ускоренный перевод российской системы образования на высокотехнологичный конкурентоспособный уровень и последующее вхождение Российской Федерации в топ-10 ведущих стран мира по качеству общего образования. А также развитие социокультурных навыков у подрастающего поколения, привитие патриотизма и воспитание социально-ответственной личности на основе национальных традиций и истории.

Российская система образования регламентирована государственными стандартами, опирается на законодательство РФ и нормы международного права. Поэтому россияне могут получить бесплатное дошкольное (ясли, детские сады, центры раннего развития, прогимназии), начальное, основное общее (школы), среднее и начальное профессиональное образование (училища, техникумы, колледжи).

На конкурсной основе доступны бюджетные формы обучения среднего профессионального, высшего профессионального (университеты, институты, академии) и послевузовского профессионального образования (аспирантура, докторантура) в государственных и муниципальных образовательных учреждениях.

В России есть возможность получить образование на самых ранних этапах развития - в ясли принимают детей от 1,5 лет в государственных и частных детских садах. Деятельность работы данных заведений контролируется типовым Положением о дошкольном образовательном учреждении. Оно включает в себя комплекс необходимых задач, которые с раннего возраста способствуют формированию нравственно-духовных ценностей. Программа, по которой дети обучаются до 6 лет, варьируется в зависимости от учебного заведения, направления подготовки и финансового обеспечения. В нашей стране нет строгой дисциплины, характерной для азиатских стран. Наоборот, ребенок должен познавать мир в игровой форме без внешнего давления со стороны. Центры раннего развития, призванные развивать детей, функционируют полностью на коммерческой основе и используют экспериментальные зарубежные методики. Ответственность за результат такого обучения ложится полностью на плечи родителей.

При достижении 6-летнего возраста дети поступают в школу для получения общего образования, продолжительность обучения в которой составляет от 9 до 11 лет. Каждое учебное заведение самостоятельно разрабатывает 
программу, выбирает учебные пособия, систему оценки в соответствии с Федеральными государственными образовательными стандартами (ФГОС).

В России также предусмотрено обучение вне образовательной организации - семейное и самообразование. Данная система предполагает промежуточную аттестацию в ближайшей школе, к которой ученик временно прикрепляется для сдачи экзаменов. Такая возможность доступна при достижении 15-летнего возраста.

Стратегия развития образования до 2025 г. изменила представление о самом понятии «общее образование». В связи с постоянно увеличивающимися объемами информации, которые человеческий мозг физически не способен обрабатывать самостоятельно, стратегия предполагает подготовку узкоквалифицированных специалистов на самом раннем этапе обучения. Система «ПОТОК» («Персонализированная образовательная траектория в открытых коллективах») позволяет ученикам самостоятельно выбирать профиль обучения, количество дисциплин, учебные аудитории и другие места для получения знаний, не связанные с учебным заведением, а также преподавателей. Роль учителя, соответственно, изменяется - он становится наставником или коучером, в обязанности которого не входит воспитательный аспект, он может лишь направлять учащихся в процессе самореализации.

Далее следует внедрение системы «РОСТ» («Распределенное оценивание в системе талантов») для объективной оценки учащихся разных профилей. Данный проект является экспериментальным и реализуется на площадках некоторых московских школ, впоследствии данная система будет апробирована в регионах.

В отличие от Китая важную роль в социализации российских детей и молодежи играет дополнительное образование. Оно содействует личностному и профессиональному развитию, помогает им адаптироваться в обществе, приобщает к здоровому образу жизни и служит сильной мотивацией к познанию самого себя, развитию творческих способностей.

На территории Российской Федерации действуют четыре государственных образовательных центра: Международный детский центр «Артек», Всероссийский детский центр «Смена», Образовательный центр «Сириус» и Всероссийский детский центр «Океан». На базе центров реализуются общеразвивающие и общеобразовательные программы, совместно с государственными и частными организациями учащиеся имеют возможность получить дополнительное, общее и дополнительное профессиональное образование. С 2014 г. запущена сеть детских технопарков «Кванториум», созданных в рамках новой модели детского дополнительного образования при содействии Агентства стратегических инициатив по продвижению новых проектов. Они оснащены первоклассным высокотехнологичным оборудованием. Для работы с детьми 
привлекаются эксперты ведущих инженерных, строительных, фармацевтических, ИТ-компаний для развития и воспитания высококлассных специалистов в стратегически важных областях науки и техники. Учащиеся имеют возможность заниматься бесплатно, а финансирование осуществляется за счет средств федерального и областного бюджетов. Также привлекаются заинтересованные в будущих специалистах частные и государственные учреждения.

Финальной ступенью системы образования в России является вуз. В зависимости от направления подготовки и количества абитуриентов разделяют университеты, академии и институты. Обучение проходит в два этапа: через четыре года присваивается степень «бакалавр», еще спустя два года — «магистр». Прошедшие итоговую государственную аттестацию по аккредитованной образовательной программе выпускники получают диплом государственного образца об уровне образования и квалификации.

\section{ЗАКЛЮЧЕНИЕ}

Система образования в Китае - это гармоничное сочетание исторических догм, основанных на многовековых традициях, и передовых практик развитых государств. В основу заложены базовые ценности: строгая дисциплина, патриотизм, трудолюбие, нерушимые нормы морали, этика, традиционные церемонии и обряды. Учитель («лаоши») в Китае играет важную роль в воспитании и наставлении ученика, поэтому к «вестникам знаний» относятся с большим почтением и уважением.

На данный момент Россия переживает кардинальную трансформацию системы образования. Советский подход, основанный на базовом фундаментальном образовании и всестороннем развитии, уходит в прошлое. Сейчас общеобразовательные учреждения настроены на выпуск специалистов узкой квалификации, обладающими профильными знаниями и компетенциями, актуальными в данный период времени и соответствующими запросам рынка. Роль патриотического воспитания и воспитания в целом снижается, учитель теряет свое истинное предназначение и оказывает лишь образовательные услуги, выполняя функции навигатора в информационном пространстве.

Китайская система направлена на воспитание грамотных исполнителей, беспрекословно действующих по ранее заданной инструкции. В образовательных учреждениях мало внимания уделяется развитию критического и творческого мышления. Учащиеся справляются с конкретными однотипными задачами, основанными на пройденных и закрепленных правилах, но, сталкиваясь с вариативностью решений, попадают в затруднительное положение. Разносторонне развитая личность, способная к нестандартному мышлению - непривычное для Китая понятие, но в частных образовательных учреждениях индивидуальный подход быстро набирает обороты. 
В России, наоборот, реализуемая Стратегия развития образования до 2025 г. делает акцент на развитии свободномыслящего человека, готового к постоянным переменам и непрерывному получению новых компетенций. Школа теряет монополию на предоставление образовательных услуг, активно развивается форма самообразования и занятия с коучерами на дому или онлайн. Широкий спектр учреждений дополнительного образования позволяет на раннем этапе развития определиться со своей будущей специальностью, что впоследствии позволит успешно интегрироваться в рабочий процесс.

\section{СПИСОК ЛИТЕРАТУРЫ}

Антиповский, А. А., Боревская, Н. Е., Франчук, Н. В. (1980) Политика в области науки и образования в КНР. 1949-1979. М. : Наука. 288 с.

Владимир Путин: «Современное, качественное образование должно быть доступно каждому» (2018) [Электронный ресурс] // Современная цифровая образовательная среда. 6 марта. URL: http://neorusedu.ru/news/vladimirputin-sovremennoe-kachestvennoe-obrazovanie-dolzhno-byt-dostupno-kazhdomu [архивировано в WaybackMachine] (дата обращения: 11.05.2020).

Законы об образовании в Китайской Народной Республике (б/д) [Электронный ресурс] // Санкт-Петербургский государственный университет. URL: https://spbu.ru/sites/default/files/zakon_ob_obrazovanii_v_kitayskoy_narodnoy_re spublike_rus.pdf [архивировано в WaybackMachine] (дата обращения: 11.05. 2020).

Китай отчитался об экономическом развитии за 2019-й: рост ВВП составил 6,1\% (2020) [Электронный ресурс] // ЭКД! 20 января. URL: http:// ekd.me/2020/01/kitaj-otchitalsya-ob-ekonomicheskom-razvitii-za-2019-j-rost-vvpsostavil-61/ [архивировано в WaybackMachine] (дата обращения: 11.05. 2020).

Национальный проект «Образование» 2019-2024: паспорт, цели и задачи (2019) [Электронный ресурс] // Стратегия 24. 10 января. URL: https://

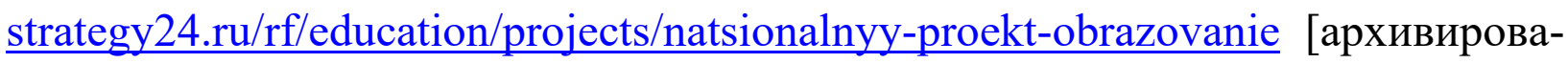
но в WaybackMachine] (дата обращения: 11.05.2020).

Экспорт Китая в 2019 году вырос на 0,5 \%, импорт упал на 2,8 \% (2020) [Электронный ресурс] // ПРАЙМ. 14 января. URL: https://1prime.ru/state_regula

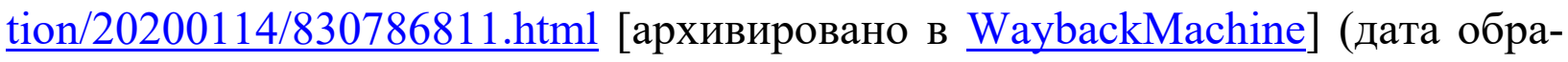
щения: 11.05.2020).

Дата поступления: 20.05.2020 2. 


\section{REFERENCES}

Antipovskii, A. A., Borevskaia, N. E. and Franchuk, N. V. (1980) Politika v oblasti nauki i obrazovaniia v KNR. 1949-1979 [Policy in the field of science and education in the PRC. 1949-1979]. Moscow : Nauka Publ. 288 p. (In Russ.).

Vladimir Putin: «Sovremennoe, kachestvennoe obrazovanie dolzhno byt' dostupno kazhdomu» [Vladimir Putin: "Modern qualitative education must be accessible to everyone"] (2018) Sovremennaia tsifrovaia obrazovatel'naia sreda [Modern digital educational environment], March 6 [online] Available at: http://neorusedu.ru/news/vladimir-putin-sovremennoe-kachestvennoe-obrazovanie-dolzhno -byt-dostupno-kazhdomu [archived in WaybackMachine] (accessed 11.05.2020). (In Russ.).

Zakony ob obrazovanii v Kitaiskoi Narodnoi Respublike [Laws on education in the People's Republic of China] (s.d.) Sankt-Peterburgskii gosudarstvennyi universitet [Saint Petersburg State University] [online] Available at: https://spbu.ru/ sites/default/files/zakon_ob_obrazovanii_v_kitayskoy_narodnoy_respublike_rus.p df [archived in WaybackMachine] (accessed 11.05.2020). (In Russ.).

Kitai otchitalsia ob ekonomicheskom razvitii za 2019-i: rost VVP sostavil 6,1 $\%$ [China reports economic development in 2019: The GDP growth was 6,1 \%] (2020) EKD!, January 20. [online] Available at: http://ekd.me/2020/01/kitaj-otchitalsya-ob-ekonomicheskom-razvitii-za-2019-j-rost-vvp-sostavil-61/ [archived in WaybackMachine] (accessed 11.05.2020). (In Russ.).

Natsional'nyi proekt «Obrazovanie» 2019-2024: pasport, tseli i zadachi [National project "Education" 2019-2024: Description, aims and objectives] (2019) Strategiia 24 [Strategy 24], January 10 [online] Available at: https://strategy24.ru/ rf/education/projects/natsionalnyy-proekt-obrazovanie [archived in WaybackMachine] (accessed 11.05.2020). (In Russ.).

Eksport Kitaia v 2019 godu vyros na 0,5 \%, import upal na 2,8 \% [China's export rose by $0,5 \%$ in 2019, import fell by 2,8\%] (2020) PRIME, January 14. [online] Available at: https://1prime.ru/state_regulation/20200114/830786811.html [archived in WaybackMachine] (accessed 11.05.2020). (In Russ.).

Submission date: 20.05.2020.

Гаврюшина Екатерина Дмитриевна - магистрант Московского гуманитарного университета. Адрес: 111395, Россия, г. Москва, ул. Юности, 5. Тел: +7 (903) 230-63-06. Эл. адрес: Kateringavr@yandex.ru. Научный руководитель: д-р филос. наук, профессор Г. П. Хорина. 
Gavriushina Ekaterina Dmitrievna, Master's Student, Moscow University for the Humanities. Postal address: 5, Yunosti St., 111395 Moscow, Russian Federation. Tel.: +7 (903) 230-63-06. E-mail: Kateringavr@yandex.ru. Research adviser: Doctor of Philosophy, Professor G. P. Khorina.

Для циитирования:

Гаврюшина Е. Д. Сравнительный анализ систем образования в Российской Федерации и Китайской Народной Республике [Электронный ресурс] // Горизонты гуманитарного знания. 2020. № 3. C. 71-79. URL: https://journals. mosgu.ru/ggz/article/view/1234 (дата обращения: дд.мм.гггг). DOI: $10.17805 /$ ggz.2020.3.6 